\title{
A Probit Latent Variable Model of Nutrition Information and Dietary Fiber Intake STOR
}

\author{
Jayachandran N. Variyam; James Blaylock; David Smallwood
}

American Journal of Agricultural Economics, Vol. 78, No. 3. (Aug., 1996), pp. 628-639.

Stable URL:

http://links.jstor.org/sici?sici=0002-9092\%28199608\%2978\%3A3\%3C628\%3AAPLVMO\%3E2.0.CO\%3B2-O

American Journal of Agricultural Economics is currently published by American Agricultural Economics Association.

Your use of the JSTOR archive indicates your acceptance of JSTOR's Terms and Conditions of Use, available at

http://www.jstor.org/about/terms.html. JSTOR's Terms and Conditions of Use provides, in part, that unless you have obtained prior permission, you may not download an entire issue of a journal or multiple copies of articles, and you may use content in the JSTOR archive only for your personal, non-commercial use.

Please contact the publisher regarding any further use of this work. Publisher contact information may be obtained at http://www.jstor.org/journals/aaea.html.

Each copy of any part of a JSTOR transmission must contain the same copyright notice that appears on the screen or printed page of such transmission.

The JSTOR Archive is a trusted digital repository providing for long-term preservation and access to leading academic journals and scholarly literature from around the world. The Archive is supported by libraries, scholarly societies, publishers, and foundations. It is an initiative of JSTOR, a not-for-profit organization with a mission to help the scholarly community take advantage of advances in technology. For more information regarding JSTOR, please contact support@ jstor.org. 


\title{
A Probit Latent Variable Model of Nutrition Information and Dietary Fiber Intake
}

\author{
Jayachandran N. Variyam, James Blaylock, and David Smallwood
}

\begin{abstract}
Nutrition information and intake data for a sample of U.S. household meal planners are used to estimate the effects of fiber-specific information on dietary fiber intake. The information variables are measured using survey questions on fiber content of foods, attitude toward consuming fiber-rich foods, and awareness of fiber-health links. The evidence confirms the influence of nutrition information on fiber intake. Household income, meal planner age, smoking status, vegetarian status, race, and ethnicity are major determinants of both information and intake. Education exerts a sizable intake effect by enhancing the information level. Direct and indirect effects of exogenous variables are reported.
\end{abstract}

Key words: diet, health information, nutrition education.

In recent years, there has been a dramatic increase in scientific evidence implicating dietary factors in the cause and prevention of important diseases such as cancer and heart disease. Reviewing the existing epidemiologic evidence, Willett remarks that "One clear conclusion...is that many individuals in the United States have suboptimal diets and that the potential for disease prevention by improved nutrition is substantial."

In economic terms, heart disease costs Americans an estimated $\$ 60.5$ billion in direct health care spending and lost productivity (American Heart Association). Associated costs for cancer are even higher, at $\$ 104$ billion (American Cancer Society). Estimates of deaths from these diseases attributable to dietary factors range from $22 \%$ to $30 \%$ of cardiovascular deaths to $20 \%$ to $60 \%$ of fatal cancers (McGinnis and Foege).

The increased understanding of diet-disease relationships and the associated costs to society have led to numerous educational campaigns to

Jayachandran N. Variyam is an agricultural economist with the Department of Agricultural Economics at the University of Kentucky and at the U.S. Department of Agriculture's Economic Research Service; James Blaylock and David Smallwood are agricultural economists at the U.S. Department of Agriculture's Economic Research Service.

The authors would like to thank Peter Basiotis, Betsy Frazao, Donald Rose, two anonymous reviewers, and the participants at the Diet Appraisal Research Working Group seminar for their helpful comments and suggestions. The views expressed in this paper are those of the authors and do not reflect the views of the Economic Research Service or the U.S. Department of Agriculture. change the dietary habits of the American public. While these campaigns have certainly heightened the media and public interest in diet-disease relationships, questions remain regarding the effect of nutrition information levels on individual dietary behavior. Presumably, heightened awareness of diet-disease relationships, better attitudes about healthy eating, and better knowledge of food composition lead to better food choices; but do they? and if so, how? Answers are crucial for designing and targeting nutrition education programs, for food marketing and promotion, and for forecasting food consumption trends.

Although economists have addressed nutrient intake issues (Behrman and Deolalikar 1988), until recently not much attention has been focused on the information-intake relationship. Among recent studies that have looked at the relationship, Brown and Schrader found that over the 1955-87 period, a cholesterol information index based on medical journal articles had a significant negative effect on egg consumption. Capps and Schmitz found significant effects for Brown and Schrader's cholesterol information index on the demand for pork, poultry, and fish. Jensen, Kesavan, and Johnson found that consumer attitudes had a significant effect on the demand for dairy products. While Gould and Lin found intake of total and saturated fat to depend on health knowledge, Putler 
and Frazao concluded that womens' diet-disease awareness level had little impact on their net dietary fat intake.

In this paper we focus on a dietary component that has received widespread publicity in the past few years: dietary fiber. We estimate the relationship between the fiber-specific nutrition information level of a sample of U.S. household meal planners and their dietary fiber intake. Recent research has linked fiber-rich diets to lower incidence of some cancers and reduced blood cholesterol levels (Block, Patterson, and Subar; U.S. Dept. of Health and Human Services 1988, 1991). Americans, however, average only 12 to 13 grams of dietary fiber daily, much below the 20 to 30 grams recommended by the National Cancer Institute.

The information variables are measured from meal planners' responses to a series of questions on fiber content of foods, attitude toward consuming fiber-rich foods, and awareness of fiber-health links. Since the response choices are discrete, a probit latent variable model is used to specify the measurement relations between the indicator questions and the underlying information variables. Our approach is similar to recent attempts by economists to incorporate attitudinal variables in consumer choice analysis (Train, McFadden, and Goett). We treat the information variables as endogenous and separate the indirect effects of various exogenous variables on intake (acting through information variables) from the direct effects of exogenous variables on intake.

\section{Conceptual Background}

Theory of household production developed by Becker and the characteristics model of consumer demand developed by Lancaster have provided the conceptual framework for much of the economic analyses of health inputs and outcomes (Behrman and Deolalikar 1988, Pitt and Rosenzweig). In this framework, households combine various inputs to produce "commodities," including the health of family members, so as to maximize a joint utility function. Some of the inputs (e.g., food) derive their value by supplying characteristics (nutrients) necessary for the production of some commodities (health). Subject to the constraints of technology and resources, household utility maximization generates individual and household demand functions for the inputs and characteristics.

Assume that a representative household with $T$ members maximizes the joint utility function

$$
\max _{F, z} \mathrm{U}=\mathrm{U}(\mathbf{F}, \mathbf{z}, \mathbf{h}), \mathrm{U}^{\prime}>0, \mathrm{U}^{\prime \prime}<0
$$

where $\mathbf{F}$ is a matrix of foods consumed, and $\mathbf{z}$ and $h$ are vectors of nonfoods and health status of each family member. Health and food intakes enter directly into the utility function because good health is valued in itself and because foods are consumed for reasons other than their nutritional value such as taste.

Given household income and market prices, preference function (1) is maximized, subject to three sets of constraints. First, the health of each family member is constrained by the health production technology:

$$
h_{t}=h\left(\mathbf{c}_{\mathrm{t}}, \mathbf{g}_{\mathrm{t}} \mid \mathbf{x}_{\mathrm{t}}, u_{t}\right), t=1, \ldots, T
$$

where $\mathbf{c}_{\mathbf{t}}$ is a vector of nutrients consumed, and $\mathbf{g}_{\mathbf{t}}$ is a vector of nonfood health inputs such as exercise and medical services. The efficiency of producing health from $\mathbf{c}_{t}$ and $g_{t}$ is conditional on $\mathbf{x}_{t}$, a vector of personal and household characteristics, and $u_{t}$, an exogenous health endowment beyond the individual's or household's control.

Second, expenditures are constrained to equal household income: $\mathbf{i}\left(\mathbf{F} \mathbf{p}_{\mathbf{F}}+\mathbf{z} p_{z}\right)=I$, where $\mathbf{p}_{\mathbf{F}}$ and $p_{z}$ denote food and nonfood prices, $I$ is household income, and $\mathbf{i}$ is a unit vector. Third, nutrient inputs into the health production function are constrained by the production technology: $\mathbf{c}_{\mathbf{t}}=\mathbf{Q} \mathbf{f}_{t}$, where $\mathbf{Q}$ is a matrix of fixed weights representing nutrient levels in each food and $\mathbf{f}_{t}$ is the vector of food consumed by the $t$ th household member.

Under the assumption that the relevant functions have desirable properties to ensure unique interior solutions, the first-order conditions for the maximization of equation (1) subject to the three constraints give, among other relations, member-specific nutrient demand equations as a function of prices, income, personal and household characteristics, and $u_{t}$.

Introducing nutrition information explicitly into the model reflects its role as a factor mediating part of the causality from $\mathbf{x}$ to $h$. For example, consider a key component of $\mathbf{x}$ : education. More educated persons are more efficient producers of health because they are more informed about the true effects of inputs on health; they have higher allocative efficiency, i.e., ability to select a better input mix. Education, therefore, affects health through information. Other personal characteristics that influence an individual's acquisition and use of information (e.g., income) also play a similar role in the production of health. 
Making the role of information explicit, the reduced-form nutrient demand functions for the $t$ th household member may be written as

$$
\mathbf{c}_{\mathbf{t}}=c\left(\mathbf{p}, I \mid \mathbf{x}_{\mathbf{t}}, \boldsymbol{\eta}_{\mathbf{t}}, u_{t}\right)
$$

where $\mathbf{p}$ is a vector of prices, $I$ is the household income, and $\eta_{t}$ is a vector of nutrition information variables.

\section{Data and Empirical Model}

Our data are from the 1989 and 1990 Continuing Survey of Food Intake of Individuals (CSFII) and the companion Diet and Health Knowledge Survey (DHKS) conducted by the Human Nutrition Information Service (HNIS) of the U.S. Department of Agriculture. The CSFII gathers information on the dietary intake of individuals and personal health-related data in households over a three-day period. The DHKS was designed so that information from it could be linked to information on food consumption from CSFII. Individuals identified in the CSFII as the main meal planner/preparer for the household were contacted about six weeks after the CSFII and asked a series of questions about their diet and health knowledge, awareness, and attitudes.

To maintain a consistent linkage between these two surveys, our analysis is restricted to include only the main meal planner/preparer that reported three days of complete intake data. After merging DHKS data for 1989 and 1990 and eliminating cases with missing values, our final sample consists of 2,466 observations out of 2,984 with complete three-day intake.

Nutrient intake is measured by summing the nutrient levels in each food reported by a respondent. Three-day average dietary fiber intake and fiber density (grams of dietary fiber consumed per 1,000 kilo calories of energy) for our sample are reported in the first row of table 1. On average, the respondents consume 12.1 grams of dietary fiber; the National Cancer Institute recommends 20 to 30 grams for a 2,000 calorie diet.

To measure meal planners' fiber information level, we use the fiber-related DHKS questions listed in table 1 . These questions measure three distinct dimensions of fiber information: $(i)$ five binary choice questions measure knowledge about sources of dietary fiber, (ii) one binary choice question indicates awareness of health problems due to insufficient fiber intake, and (iii) three ordered polytomous choice questions measure attitude toward consuming fiberrich food.

Table 1 also reports the mean fiber densities for the categories of each fiber question. It is readily apparent that respondents with more fiber information, i.e., those choosing the correct high-fiber food, those aware of health problems related to fiber, and those who consider it important or very important to eat fiber-rich food, tend to have higher fiber consumption.

We make two abstractions in specifying an empirical version of equation (3) for modeling dietary fiber intake. First, since our analysis is concerned with intake choices made at a given point in time by a cross-section of households, we assume that there is limited price variation across households. The extant price variation is assumed to be captured by terms for geographic region and location of the household. Second, we focus on modeling the fiber intake of one individual, the main meal planner/preparer, per household because this is the only individual for which we have nutrition information data.

Suppose $c_{i}$ is a measure of dietary fiber consumed by the $i$ th meal planner, $i=1, \ldots, N$. Let $\eta_{\mathbf{i}}=\left(\eta_{i 1} \eta_{i 2} \eta_{i 3}\right)^{\prime}$ be a vector of measurements on the three fiber information variables, knowledge, awareness, and attitude. Our empirical model is specified as

$$
\begin{aligned}
& c_{i}=\beta_{0}+\boldsymbol{\beta}_{1}^{\prime} \eta_{\mathbf{i}}+\boldsymbol{\beta}_{2}^{\prime} \mathbf{x}_{\mathbf{i}}+\xi_{i}^{*} \\
& \eta_{i k}=\gamma_{0 k}+\boldsymbol{\gamma}_{\mathbf{1}}^{\prime} \mathbf{x}_{\mathbf{i}}+\zeta_{i k}, k=1,2,3
\end{aligned}
$$

where $\mathbf{x}_{\mathbf{i}}$ is a $(P \times 1)$ vector of exogenous variables, $\boldsymbol{\beta}_{0}$ and $\gamma_{0 k}$ are scalar intercepts, $\boldsymbol{\beta}_{\mathbf{1}}, \boldsymbol{\beta}_{2}$, and $\gamma_{1 \mathrm{k}}$ are conformable vectors of structural coefficients, and $\xi_{i}^{*}$ and $\zeta_{i k}$ are error terms distributed independently and identically across individuals. The information variables, $\eta_{i k}$, are allowed to be correlated for the same individual and uncorrelated otherwise. Additionally, if $\operatorname{cov}\left(\xi_{i}^{*}\right.$, $\left.\zeta_{i k}\right)=0$ for all $i, j, k$, the model is fully recursive and identified. However, if $\operatorname{cov}\left(\xi_{i}^{*}, \zeta_{i k}\right)$ is unrestricted for all $i=j$ and $k=1,2,3, \boldsymbol{\beta}_{2}$ and $\gamma_{1 \mathrm{k}}$ must contain restrictions to achieve identification.

If $\eta_{i k}$ are observed, the model can be estimated readily by two-stage least squares. In our case, however, $\eta_{i k}$ are not directly observed, but indirectly measurable using observable responses to the indicator questions. A measurement model relating the indicators to the underlying unobservables is specified as 
Table 1. Dietary Fiber Intake and Information Questions: Sample Statistics

\begin{tabular}{lcc}
\hline${\text { Dietary fiber intake }(\text { grams })^{\mathrm{a}}}$ & Mean & Std. Dev. \\
\hline & 12.1 & 6.3 \\
Dietary fiber information (percentage) $^{\mathrm{b}}$ & $(7.9)$ & $(3.5)$ \\
\hline 1. Knowledge: Which has more fiber? & & \\
& Incorrect & Correct \\
\cline { 2 - 3 } a. Meat/Fruit & 20.4 & 79.6 \\
b. Cornflakes/Oatmeal & $(7.2)$ & $(8.0)$ \\
c. White/Whole wheat bread & 18.3 & 81.7 \\
& $(7.7)$ & $(7.9)$ \\
d. Orange juice/Apple & 6.7 & 93.3 \\
e. Pretzels/Popcorn & $(6.8)$ & $(7.9)$ \\
& 23.9 & 76.1 \\
& $(7.7)$ & $(7.9)$ \\
& 23.7 & 76.3 \\
& $(7.2)$ & $(8.0)$
\end{tabular}

2. Awareness: Have you heard about any health problems related to:

a. How much fiber a person eats?

\begin{tabular}{|c|c|}
\hline No & Yes \\
\hline $\begin{array}{c}49.8 \\
(7.6)\end{array}$ & $\begin{array}{c}50.2 \\
(8.1)\end{array}$ \\
\hline
\end{tabular}

3. Attitude: How important it is to you to?

a. Eat foods with adequate fiber?

b. Eat at least five servings a day of fruits and vegetables?

c. Eat at least six servings a day of breads, cereals, and other grain products?

\begin{tabular}{cccccc}
$\begin{array}{c}\text { Not at all } \\
\text { Important } \\
1\end{array}$ & 2 & 3 & 4 & 5 & $\begin{array}{c}\text { Very } \\
\text { Important } \\
6\end{array}$ \\
\hline 3.9 & 3.8 & 11.8 & 16.7 & 20.9 & 42.9 \\
$(7.7)$ & $(6.4)$ & $(6.9)$ & $(7.5)$ & $(8.0)$ & $(8.4)$ \\
15.7 & 8.4 & 13.1 & 17.6 & 14.6 & 30.7 \\
$(7.7)$ & $(6.9)$ & $(7.1)$ & $(7.3)$ & $(8.1)$ & $(8.9)$ \\
10.0 & 12.3 & 18.3 & 21.9 & 13.7 & 23.7 \\
$(7.4)$ & $(7.1)$ & $(7.7)$ & $(7.8)$ & $(8.1)$ & $(8.6)$ \\
& & & & &
\end{tabular}

Note: Sample size is 2,466 .

${ }^{\text {a }}$ Figures in parentheses give the mean and standard deviation of fiber density (grams of fiber per 1,000 kilo calories).

${ }^{b}$ Figures in parentheses give the mean fiber density for the category.

(6)

$$
y_{i k m}^{*}=\lambda_{0 k m}+\lambda_{1 k m} \eta_{i k}+\varepsilon_{i k m}^{*}
$$

where $y_{i k m}^{*}$ is a measure of response to the $m$ th indicator question of the $k$ th information variable, $\lambda_{0 k m}$ is a scalar intercept, $\lambda_{1 k m}$ is a scalar "loading" parameter, $\varepsilon_{i k m}^{*}$ is an independently and identically distributed measurement error term, and $m=1, \ldots, 5$ for $k=1, m=1$ for $k=$ 2 , and $m=1,2,3$ for $k=3$. The measurement errors are assumed to be uncorrelated with each other as well as with the error terms in equations (4) and (5).

Identification of parameters in equations (4)-
(6) requires that each $\eta_{i k}$ has two or more indicators and that the origin and scale of each $\eta_{i k}$ is fixed (Bollen, pp. 238-54). We normalize $\eta_{i 1}$ (knowledge) by setting $\lambda_{013}=0$ and $\lambda_{113}=1$ for one of its indicators $y_{i 13}^{*}$ (white/whole wheat bread), and $\eta_{i 3}$ (attitude) by setting $\lambda_{031}=0$ and $\lambda_{131}=1$ for one of its indicators $y_{i 31}^{*}$ (foods with adequate fiber). For $\eta_{i 2}$ (awareness) besides $\lambda_{021}=0$ and $\lambda_{121}=1$, an additional restriction that $\varepsilon_{i 21}^{*}=0$ is imposed since it has only one indicator. Thus, the awareness variable is assumed to be measured without error so that $y_{i 21}^{*}=\eta_{i 2}$. 
If responses $y_{i k m}^{*}$ are observed and continuous, model (4)-(6) can be estimated by a straightforward application of maximum likelihood. The responses to our indicator questions, however, are discrete. In this case, $y_{i k m}^{*}$ may be viewed as underlying indices which generate binary or ordinal outcomes as they cross some unknown thresholds. As in the usual probit model, we assume that for knowledge and awareness the observed binary response, denoted $y_{i k m}$, is generated by

$$
y_{i k m}=1 \text { if } y_{i k m}^{*}>\mu_{k m}, 0 \text { otherwise, } k=1,2
$$

and for attitude, the observed ordinal response, denoted $y_{i 3 \mathrm{~m}}$, is generated by

$$
y_{i 3 m}=r \text { if } \mu_{3 m, r-1} \leq y_{i 3 m}^{*}<\mu_{3 m, r}, r=1, \ldots, 6
$$

where $\mu_{k m}$ and $\mu_{3 m, r}$ are unknown threshold values, and $\mu_{3 m, 0}=-\infty, \mu_{3 m, 6}=+\infty$.

From equations (4)-(6), we have the reducedform equations

$$
c_{i}=\alpha_{0}+\boldsymbol{\alpha}_{1}^{\prime} \mathbf{x}_{\mathbf{i}}+\xi_{i}
$$

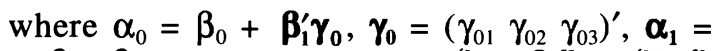
$\Gamma_{1}^{\prime} \boldsymbol{\beta}_{1}+\boldsymbol{\beta}_{2}, \Gamma_{1}^{\prime}=\left(\gamma_{1} \gamma_{2} \gamma_{3}\right)$, and $\xi_{i}=\beta_{1}^{\prime} \zeta_{1}+\xi_{i}^{*}, \zeta_{i}$ $=\left(\zeta_{i 1} \zeta_{i 2} \zeta_{i 3}\right)^{\prime}$, and

$$
y_{i k m}^{*}=\pi_{0 k m}+\pi_{1 \mathbf{k m}}^{\prime} \mathbf{x}_{\mathbf{i}}+\varepsilon_{i k m}
$$

where $\pi_{0 k m}=\lambda_{0 k m}+\lambda_{1 k m} \gamma_{1 k}, \pi_{1 \mathrm{~km}}=\lambda_{1 k m} \gamma_{1 \mathrm{k}}$ and $\varepsilon_{i k m}=\lambda_{1 k m} \zeta_{i k}+\varepsilon_{i k m}^{*}$.

Since the reduced-form errors in equations (9) and (10) are correlated, the structural parameters of interest in equations (4)-(6) are embedded nonlinearly in $M=10$ correlated equations for the observables. Recovering the structural parameters from equations (9) and (10) by full information maximum likelihood is computationally complex except for small values of $M$. Computationally tractable estimation procedures for models of this type, based on the minimum distance (or minimum chi-square) estimator, have been proposed by Lee, by Muthen (1983, 1984), and by Sobel and Arminger. In general, the procedures use the estimates of the reduced-form parameters and the restrictions imposed by the structural model to estimate all the structural parameters by iteratively minimizing a minimum distance function (Chamberlain, Newey). The estimator and the estimation procedure are described in an appendix available from the authors upon request.

\section{Empirical Results}

The exogenous variables hypothesized to affect information and/or intake are listed in table 2. Annual household income, household size, the main meal planner's age, and his or her body mass index (BMI) are continuous variables and the others are dummy variables. Region, location of the household, and the main meal planner's education have multiple categories and are represented by groups of dummy variables. BMI is a ratio of the body weight (in kilograms) divided by the square of height (in meters).

The expected effect of income is complicated. On the one hand, higher income may give better access to dietary information and thus affect knowledge, attitude, and consumption positively. On the other hand, fiber-rich foods such as breads, grains, and cereals may be inferior goods whose consumption falls as

\begin{tabular}{|c|c|c|}
\hline Variable & Mean & Std. Dev. \\
\hline \multicolumn{3}{|l|}{ Household characteristics } \\
\hline Income (thousand dollars) & 23.18 & 21.70 \\
\hline Program $^{\mathrm{a}}$ & 0.07 & 0.26 \\
\hline Household size & 2.63 & 1.47 \\
\hline Children & 0.41 & 0.49 \\
\hline Midwest $^{\mathrm{b}}$ & 0.25 & 0.43 \\
\hline South & 0.34 & 0.47 \\
\hline West & 0.20 & 0.40 \\
\hline Suburban $^{\mathrm{c}}$ & 0.47 & 0.50 \\
\hline Nonmetro & 0.23 & 0.42 \\
\hline
\end{tabular}
income increases. A priori information is lacking on which of these effects will dominate.

\section{Table 2. Explanatory Variables}

Meal planner sociodemographic characteristics

$\begin{array}{lrr}\text { Female } & 0.80 & 0.40 \\ \text { Black } & 0.15 & 0.35 \\ \text { Hispanic } & 0.06 & 0.23 \\ \text { High school }^{\text {d }} & 0.51 & 0.50 \\ \text { College } & 0.34 & 0.47 \\ \text { Postgraduate }_{\text {Age (years) }} & 0.10 & 0.31 \\ \text { Not employed } & 47.56 & 18.33 \\ & 0.43 & 0.50\end{array}$

Meal planner health-diet characteristics

$\begin{array}{lrr}\text { Smoker } & 0.26 & 0.44 \\ \text { Vegetarian } & 0.03 & 0.18 \\ \text { Special diet } & 0.16 & 0.37 \\ \text { Fiber supplement } & 0.06 & 0.24 \\ \text { BMI (body mass index) } & 25.70 & 5.51\end{array}$

a Participated in Food Stamp Program or Women, Infants, and Children (WIC) Program.

b Northeast omitted.

${ }^{c}$ City omitted.

${ }^{d}$ Less than high school omitted. 
Among sociodemographic variables, we expect the education variables to have positive effects by enabling better acquisition and processing of nutrition information. The traditional role that females have played in food preparation/shopping leads us to expect that they have higher stocks of nutrition information than do males. The race and age variables are expected to capture variations in fiber information, food preferences, and consumption induced by cultural backgrounds and dietary habits. If the main meal planner is not employed outside the home, this is likely to impact time allocation for food preparation versus other activities, and hence may affect intake.

Since grains, fruits, and vegetables are the major sources of dietary fiber, we expect vegetarians to be more familiar and informed about these fiber-rich foods and have relatively higher dietary fiber consumption. Conversely, smokers are probably less concerned about health issues and hence possess less dietary information. To the extent that dietary habits of smokers differ from nonsmokers, fiber intake also would be affected.

Variables "special diet" and "fiber supplement" are included to control for the likely higher fiber densities of respondents on a diet or the effects of taking fiber supplements. Body mass index is included to control for the effects of variations in the amount of food consumed due to weight and height. We expect BMI to be negatively correlated with fiber intake because complex carbohydrates are bulky and less energy-dense than fats. Thus, individuals with higher BMIs may receive more of their calories from foods high in fats and protein and fewer calories from foods rich in complex carbohydrates (Dattilo).

Table 3 reports estimates for the fiber intake equation under two specifications of our model. The specifications differ with respect to the information variables included in the intake equation. The intake effects of education, gender, and program participation are assumed to be purely due to informational differences. Therefore, under both specifications, these variables enter the information equations only.

The last two rows of table 3 contain a pseudo- $\mathrm{R}^{2}$ for the entire model, denoted $R_{m}^{2}$, and the Akaike Information Criterion (AIC). The quantity $R_{m}^{2}$ is computed similar to McFadden's $\mathbf{R}^{2}$ :

$$
R_{m}^{2}=\frac{Q\left(\hat{\delta}_{b}\right)-Q\left(\hat{\delta}_{m}\right)}{Q\left(\hat{\delta}_{b}\right)}
$$

where $Q\left(\delta_{b}\right)$ and $Q\left(\delta_{m}\right)$ are the minimized values of the minimum distance function for a base model $b$ and the hypothesized model $m$ (Bollen). In the base model, the structural and measurement equations have been restricted to include only the intercepts.

The measurement equations are normalized by setting $\lambda_{0 \mathrm{~km}}=0$ and $\lambda_{1 \mathrm{~km}}=1$ for one indicator per information variable. With this normalization, a positive coefficient for the information variable in the intake equation implies that dietary fiber intake rises in response to a rising information level.

The intake equation under the first specification, model I, includes all three fiber information variables. The awareness coefficient is significant at the $1 \%$ level and the attitude coefficient is significant at the $10 \%$ level. The knowledge coefficient, however, is insignificant. This result could be due to the redundancy of information captured by the knowledge variable, given the awareness and attitude variables. We test this supposition by reestimating model I after dropping the knowledge variable from the intake equation. Results appear under model II in table 3. The sizes of awareness and attitude coefficients are $37 \%$ and $31 \%$ higher, respectively, compared to model I. The sum of the fiber information coefficients, however, remains approximately the same: 0.264 under model I and 0.266 under model II. Model II has the same $R_{m}^{2}$ as model I, but has a lower AIC, indicating a better fit. Therefore, we choose model II as our preferred specification and discuss results for this model below.

Evidence that diet-disease awareness has the largest impact on fiber intake is not surprising given that avoiding health problems has the most immediate and transparent economic benefits to the consumer. Therefore, consumers possessing this type of information may be expected to actively change their dietary patterns compared to consumers who do not have this information, or to those who have only general notions about the benefits of dietary fiber. This suggests that nutrition education programs aimed at increasing the general awareness of linkages between fiber and health disease will likely have the highest payoffs in terms of raising dietary fiber intake levels. The results also suggest that there is a distinct attitudinal dimension beyond disease awareness that influences fiber consumption. Nutrition education strategies emphasizing general attitudinal messages such as five-a-day intake are likely to have greater impact in modifying dietary patterns than strategies emphasizing specialized 
Table 3. Estimates of Dietary Fiber Intake Equation (Absolute t-values in Parentheses)

\begin{tabular}{lrrrr}
\hline $\begin{array}{l}\text { Explanatory } \\
\text { Variable }\end{array}$ & \multicolumn{2}{c}{ Model I } & \multicolumn{2}{c}{ Model II } \\
\hline Constant & -5.259 & $(26.31)$ & -5.179 & $(26.27)$ \\
Knowledge $\left(\eta_{1}\right)$ & 0.067 & $(1.13)$ & - & \\
Awareness $\left(\eta_{2}\right)$ & 0.126 & $(2.53)$ & 0.173 & $(5.35)$ \\
Attitude $\left(\eta_{3}\right)$ & 0.071 & $(1.44)$ & 0.093 & $(1.90)$ \\
Log income & -0.046 & $(3.41)$ & -0.040 & $(3.10)$ \\
Household size & -0.001 & $(0.06)$ & 0.001 & $(0.09)$ \\
Children & -0.044 & $(1.60)$ & -0.053 & $(1.90)$ \\
Midwest & -0.001 & $(0.02)$ & -0.017 & $(0.62)$ \\
South & 0.011 & $(0.41)$ & -0.005 & $(0.21)$ \\
West & 0.050 & $(1.33)$ & 0.022 & $(0.69)$ \\
Suburban & 0.020 & $(1.09)$ & 0.024 & $(1.28)$ \\
Nonmetro & -0.016 & $(0.74)$ & -0.013 & $(0.59)$ \\
Black & -0.083 & $(3.07)$ & -0.100 & $(4.25)$ \\
Hispanic & 0.110 & $(2.89)$ & 0.094 & $(2.53)$ \\
Log age & 0.241 & $(7.01)$ & 0.227 & $(6.63)$ \\
Not employed & 0.029 & $(1.64)$ & 0.026 & $(1.40)$ \\
Smoker & -0.078 & $(4.05)$ & -0.076 & $(3.68)$ \\
Vegetarian & 0.128 & $(3.30)$ & 0.133 & $(3.16)$ \\
Diet & -0.029 & $(1.21)$ & -0.033 & $(1.31)$ \\
Supplement & 0.019 & $(0.58)$ & 0.011 & $(0.33)$ \\
Log BMI & -0.114 & $(3.31)$ & -0.113 & $(3.28)$ \\
R ${ }_{m}^{2}$ & 0.777 & & 0.777 & \\
AIC & 744.710 & & 743.842 & \\
\hline
\end{tabular}

Notes: The dependent variable is log fiber density. The sample size is 2,466 .

knowledge about the nutrient content of foods.

Table 4 reports estimates for the information equations of model II. The intake equation estimates reported in table 3 capture the variables' direct effect on fiber intake. These variables also affect fiber intake indirectly through their effects on the fiber information variables. These separate effects can be seen by rewriting the reduced-form consumption equation (9) as follows:

$$
c_{i}=\alpha_{0}+\beta_{11} \gamma_{1}^{\prime} \mathbf{x}_{\mathbf{i}}+\beta_{12} \boldsymbol{\gamma}_{2}^{\prime} \mathbf{x}_{\mathbf{i}}+\boldsymbol{\beta}_{13} \boldsymbol{\gamma}_{3}^{\prime} \mathbf{x}_{\mathbf{i}}+\boldsymbol{\beta}_{2} \mathbf{x}_{\mathbf{i}}+\xi_{i}
$$

where $\beta_{11}, \beta_{12}$, and $\beta_{13}$ are the coefficients of knowledge, disease awareness, and attitude variables. The second to fourth terms on the right-hand side represent the indirect effect of the observed explanatory variables on intake, and the fifth term represents the direct effect. The sum of indirect and direct effects gives the total effect of exogenous variables on intake. The indirect and total effects for model II appear in table 5. For convenience, the direct effects are repeated in the first column of the table.

The coefficients of the dummy variables in table 5 can be interpreted as the approximate percent change in fiber density for the respective category compared to the base category (the exact percent change is given by $100\{\exp (\beta)-1\}$, where $\beta$ is the coefficient estimate). The coefficients for income, age, and BMI are elasticities. In table 6, we translate selected coefficient estimates to their quantitative effects by computing the changes in predicted fiber density due to changes in an explanatory variable, holding other variables constant.

Household income, the primary economic variable, has a significant negative total effect on dietary fiber intake. Controlling for information and other factors, the income elasticity is -0.04 which implies a reduction in fiber density by about 0.04 grams for a $10 \%$ rise in income. The direct effect of income dominates the total effect, confirming that as income rises, consumption might be shifting to foods low in fiber. Earlier findings in a developing country context have indicated that an increase in income by itself may not be enough to improve nutrition (Behrman and Deolalikar 1987). Our result implies that these findings may be equally applicable to developed countries, at least for dietary fiber. The effect of income on information variables is interesting in one im- 
Table 4. Model II Estimates of Fiber Information Equations (Absolute t-values in Parentheses)

\begin{tabular}{|c|c|c|c|c|c|c|}
\hline \multirow{2}{*}{$\begin{array}{l}\text { Explanatory } \\
\text { Variable }\end{array}$} & \multicolumn{2}{|c|}{$\begin{array}{c}\text { Knowledge } \\
\left(\eta_{1}\right)\end{array}$} & \multicolumn{2}{|c|}{$\begin{array}{c}\text { Awareness } \\
\left(\eta_{2}\right)\end{array}$} & \multicolumn{2}{|c|}{$\begin{array}{l}\text { Attitude } \\
\qquad\left(\eta_{3}\right)\end{array}$} \\
\hline & 0.160 & $(0.39)$ & -1.662 & $(3.59)$ & 0.146 & $(0.38)$ \\
\hline Log income & 0.130 & (4.17) & 0.078 & $(2.04)$ & -0.070 & $(2.50)$ \\
\hline Program & -0.245 & $(3.14)$ & -0.337 & $(3.50)$ & -0.104 & (1.34) \\
\hline Household size & 0.025 & $(1.17)$ & 0.005 & $(0.17)$ & 0.022 & $(1.09)$ \\
\hline Children & -0.052 & $(0.79)$ & 0.131 & (1.64) & 0.079 & (1.31) \\
\hline Midwest & -0.057 & $(0.87)$ & 0.286 & $(3.90)$ & -0.063 & (1.14) \\
\hline South & -0.207 & $(3.49)$ & 0.065 & $(0.92)$ & -0.082 & $(1.57)$ \\
\hline West & -0.023 & $(0.37)$ & 0.477 & $(6.03)$ & 0.274 & $(4.59)$ \\
\hline Suburb & 0.085 & (1.74) & 0.036 & $(0.60)$ & -0.002 & $(0.04)$ \\
\hline Nonmetro & 0.131 & $(2.30)$ & 0.136 & (1.94) & -0.007 & $(0.13)$ \\
\hline Female & 0.389 & $(7.40)$ & 0.144 & $(2.47)$ & 0.226 & $(4.53)$ \\
\hline Black & -0.370 & $(6.35)$ & -0.155 & $(2.09)$ & -0.024 & $(0.47)$ \\
\hline Hispanic & -0.494 & $(6.01)$ & -0.336 & $(3.26)$ & -0.190 & $(2.42)$ \\
\hline High school & -0.051 & $(0.56)$ & 0.023 & $(0.20)$ & 0.655 & $(7.04)$ \\
\hline College & 0.301 & $(3.04)$ & 0.353 & $(2.84)$ & 0.583 & $(5.84)$ \\
\hline Postgraduate & 0.439 & $(3.64)$ & 0.881 & $(5.97)$ & 0.675 & $(6.03)$ \\
\hline Log age & -0.020 & $(0.32)$ & 0.109 & (1.34) & 0.419 & $(6.44)$ \\
\hline Not employed & -0.049 & $(1.05)$ & 0.022 & $(0.37)$ & 0.005 & $(0.11)$ \\
\hline Smoker & -0.116 & $(2.54)$ & -0.172 & $(3.01)$ & -0.156 & (3.78) \\
\hline Vegetarian & 0.426 & (3.81) & 0.263 & $(1.78)$ & 0.337 & $(4.39)$ \\
\hline Diet & 0.259 & $(4.38)$ & 0.331 & $(4.70)$ & 0.246 & $(5.05)$ \\
\hline Supplement & 0.031 & $(0.35)$ & 0.212 & (1.94) & 0.222 & $(2.86)$ \\
\hline Conversion factor ${ }^{\mathrm{a}}$ & 0.106 & & 0.399 & & 0.375 & \\
\hline
\end{tabular}

a Conversion factor multiplied by a coefficient estimate gives the predicted change in probability of the normalized indicator question due to a change in the corresponding explanatory variable. The reported conversion factors apply to the following indicators in table 1 : white/ whole wheat bread for $\eta_{1}$, fiber-related health problems for $\eta_{2}$, and foods with adequate fiber for $\eta_{3}$. Since the attitude indicator is ordered, it has six conversion factors corresponding to the six response categories (see table 1). The figures reported above are for the sixth category ("very important").

portant respect: only income has significant but opposite effects on knowledge/awareness (positive) and attitude (negative). This may be because higher-income individuals tend to view fiber-rich foods, such as many grain products, as inferior goods.

Fiber density of meal planners from households participating in the Food Stamp or Women Infants and Childiren (WIC) programs is about a half-gram lower than respondents from nonparticipating households. Most of the lower consumption occurs through lower fiberhealth awareness. The attitude effect is insignificant. This is consistent with the result in table 4 that attitude toward consuming fiberrich food is not significantly different between program participants and nonparticipants. Overall, the results suggest that if participants are targeted for nutrition education, greater emphasis on increasing disease awareness and fiber knowledge would be desirable.

Among other household variables, household size does not have much direct or indirect effect on fiber intake. Presence of children, however, has a negative direct effect on fiber in- take. When the dummy variable for presence of children is dropped, the effect of household size increases, especially on attitude toward consuming fiber-rich food which becomes positive and significant. This is likely due to the collinearity between presence of children and household size. Among regions, only the West has a significant total effect. Meal planners from the West tend to have a $14 \%$ higher fiber intake compared to meal planners from the Northeast. This translates, on average, to one gram of dietary fiber per 1,000 calories of energy intake. About $64 \%$, or 0.63 , grams of this additional fiber intake for West is due to greater awareness of health problems related to fiber. Suburban residents have about 3\% higher fiber density than city residents while fiber densities of nonmetro residents and city residents are not significantly different.

Among sociodemographic variables, results imply that females have a $5 \%$, or third of a gram, higher fiber density than males, contributed almost evenly by better awareness and attitude levels. Black respondents have significantly lower fiber consumption compared to 
Table 5. Model II Direct, Indirect, and Total Effects on Dietary Fiber Intake (Absolute t-values in Parentheses)

\begin{tabular}{|c|c|c|c|c|c|c|c|c|}
\hline \multirow{3}{*}{$\begin{array}{l}\text { Explanatory } \\
\text { Variable } \\
\text { Log income }\end{array}$} & \multirow{2}{*}{\multicolumn{2}{|c|}{ Direct Effect }} & \multicolumn{4}{|c|}{ Indirect Effect } & \multirow{2}{*}{\multicolumn{2}{|c|}{ Total Effect }} \\
\hline & & & \multicolumn{2}{|c|}{ Awareness } & \multicolumn{2}{|c|}{ Attitude } & & \\
\hline & -0.040 & $(3.10)$ & 0.013 & $(1.80)$ & -0.006 & $(1.51)$ & -0.033 & (3.29) \\
\hline Program & - & & -0.058 & $(3.21)$ & -0.010 & (1.11) & -0.068 & (3.62) \\
\hline Household size & 0.001 & $(0.09)$ & 0.001 & $(0.17)$ & 0.002 & $(0.93)$ & 0.004 & $(0.47)$ \\
\hline Children & -0.053 & $(1.90)$ & 0.023 & $(1.55)$ & 0.007 & $(1.09)$ & -0.023 & $(0.98)$ \\
\hline Midwest & -0.017 & $(0.62)$ & 0.050 & (3.18) & -0.006 & $(0.99)$ & 0.027 & (1.21) \\
\hline South & -0.005 & $(0.21)$ & 0.011 & $(0.91)$ & -0.008 & $(1.20)$ & -0.001 & $(0.10)$ \\
\hline West & 0.022 & $(0.69)$ & 0.082 & (3.95) & 0.025 & $(1.75)$ & 0.129 & (5.72) \\
\hline Suburban & 0.024 & $(1.28)$ & 0.006 & $(0.60)$ & -0.000 & $(0.04)$ & 0.030 & (1.87) \\
\hline Nonmetro & -0.013 & $(0.59)$ & 0.024 & $(1.83)$ & -0.001 & $(0.13)$ & 0.010 & $(0.52)$ \\
\hline Female & - & & 0.025 & $(2.33)$ & 0.021 & (1.79) & 0.046 & (3.49) \\
\hline Black & -0.100 & $(4.25)$ & -0.027 & (1.97) & -0.002 & $(0.45)$ & -0.129 & (6.54) \\
\hline Hispanic & 0.094 & $(2.53)$ & -0.058 & $(2.79)$ & -0.018 & $(1.48)$ & 0.019 & $(0.65)$ \\
\hline High school & - & & 0.004 & $(0.20)$ & 0.061 & $(1.92)$ & 0.065 & (2.23) \\
\hline College & - & & 0.061 & (2.61) & 0.054 & $(1.90)$ & 0.115 & (3.98) \\
\hline Postgraduate & - & & 0.152 & $(4.65)$ & 0.062 & $(1.89)$ & 0.215 & (5.94) \\
\hline Log age & 0.227 & $(6.63)$ & 0.019 & (1.31) & 0.039 & $(1.82)$ & 0.285 & (11.89) \\
\hline Not employed & 0.026 & $(1.40)$ & 0.004 & $(0.37)$ & 0.000 & $(0.11)$ & 0.030 & $(1.92)$ \\
\hline Smoker & -0.076 & $(3.68)$ & -0.030 & $(2.52)$ & -0.014 & $(1.71)$ & -0.120 & (7.93) \\
\hline Vegetarian & 0.133 & (3.16) & 0.045 & (1.73) & 0.031 & (1.74) & 0.209 & $(6.72)$ \\
\hline Diet & -0.033 & $(1.31)$ & 0.057 & (3.63) & 0.023 & (1.81) & 0.047 & (2.73) \\
\hline Supplement & 0.011 & $(0.33)$ & 0.037 & (1.79) & 0.021 & $(1.53)$ & 0.068 & (2.58) \\
\hline Log BMI & -0.113 & $(3.28)$ & - & & & - & -0.113 & (3.28) \\
\hline
\end{tabular}

Table 6. Average Change in Fiber Intake (in Grams per 1,000 Kilo Calories) Due to Change in Selected Explanatory Variables: Direct, Indirect, and Total Effects for Model II

\begin{tabular}{|c|c|c|c|c|}
\hline \multirow{2}{*}{$\begin{array}{l}\text { Explanatory } \\
\text { Variable }\end{array}$} & \multirow[b]{2}{*}{ Direct Effect } & \multicolumn{2}{|c|}{ Indirect Effect } & \multirow[b]{2}{*}{ Total Effect } \\
\hline & & Awareness & Attitude & \\
\hline Income & -0.030 & 0.010 & -0.005 & -0.025 \\
\hline Program & - & -0.422 & -0.070 & -0.492 \\
\hline West & 0.165 & 0.632 & 0.194 & 0.991 \\
\hline Female & - & 0.183 & 0.153 & 0.336 \\
\hline Black & -0.708 & -0.190 & -0.015 & -0.914 \\
\hline Hispanic & 0.704 & -0.434 & -0.131 & 0.139 \\
\hline High school & - & 0.029 & 0.427 & 0.456 \\
\hline College & - & 0.441 & 0.390 & 0.831 \\
\hline Postgraduate & - & 1.160 & 0.475 & 1.635 \\
\hline Age & 0.168 & 0.014 & 0.029 & 0.211 \\
\hline Not employed & 0.190 & 0.028 & 0.003 & 0.221 \\
\hline Smoker & -0.548 & -0.214 & -0.104 & -0.866 \\
\hline Vegetarian & 1.086 & 0.372 & 0.255 & 1.713 \\
\hline Diet & -0.248 & 0.431 & 0.171 & 0.354 \\
\hline Supplement & 0.083 & 0.280 & 0.157 & 0.519 \\
\hline BMI & -0.084 & - & - & -0.084 \\
\hline
\end{tabular}

Note: Figures for income, age, and BMI are for a $10 \%$ increase in the respective variable.

other races; $12 \%$ lower, or about 0.9 gram of dietary fiber per 1,000 calories. While most of this is a direct effect, $21 \%$ of this lower consumption is due to the lower awareness of black respondents regarding health problems due to fiber deficiency. It is interesting to note that the attitude effect between blacks and non-blacks is insignificant. Thus, nutrition education programs targeted toward blacks may need to emphasize fiber-health linkages. 
The effects due to the Hispanic ethnicity of respondents provide an illustration of the importance of isolating direct and indirect effects on intake. For a given level of awareness and attitude, the direct effect of Hispanic ethnicity is to increase fiber density by about $10 \%$, or 0.7 gram, over meal planners of other ethnic groups. However, Hispanics' lower levels of disease awareness and, to a lesser extent, lower levels of concern about eating fiber-rich foods exert indirect negative effects on their fiber intake, rendering their total fiber consumption not significantly different from other ethnic groups.

Years of formal education weigh heavily in favor of increased knowledge level, increased awareness, and better attitude. The college and postgraduate dummy variables are consistently significant at the $1 \%$ level. Using the conversion factor presented in the last row of table 5, a postgraduate education increases the odds of disease awareness by $35 \%$. This evidence is consistent with the findings of Kushi et al. who found that a larger proportion of respondents with high educational attainment than those with lower educational attainment were able to answer dietary knowledge questions correctly.

The differential impact of educational variables on information variables is interesting. A high school education does not increase the odds of higher knowledge of fiber-content or disease awareness vis-à-vis a lower educational level. However, having at least a high school education increases the odds of the meal planner considering it very important to consume food with adequate fiber by $25 \%$, nearly the same increase in odds for this choice due to a postgraduate education. A likely explanation for this difference is that the specificity of information associated with knowledge and awareness questions requires additional education beyond the high school level, whereas just a high school education can make a significance difference in accumulating the more general information associated with the attitude questions.

Results for the total effect of education show that a high school education adds about $7 \%$, or half a gram, of fiber density and a college education adds about $12 \%$, or 0.83 gram, of higher fiber density over the fiber density of those with less than a high school education. The effect of postgraduate education is even more substantial; the indirect effects through awareness and attitude contribute over one gram and nearly half a gram each of higher fiber density for a total of 1.64 grams for the postgraduate respondents over respondents with less than a high school education.
Dietary fiber intake increases significantly with increases in respondent's age. The total age elasticity is 0.3 , which translates to slightly more than two-tenths of a gram of higher fiber density for a $10 \%$ increase in age. Like income, the age effect is also principally direct. Unlike most previous variables, however, the contribution of indirect effect to the total effect of age is dominated by attitude. This is in line with the result in table 5 that age affects attitude much more than it affects disease awareness.

Meal planners who are not employed full time outside the home consume about 0.2 grams more fiber per 1,000 calories compared to those with outside employment. Interestingly, the entire positive effect of not being employed outside the home is direct. There is no significant difference in knowledge/awareness/ attitude levels between stay-at-home versus employed meal planners. The difference in fiber intake between these groups may be related to the differences in their time allocations for food preparation and shopping.

As expected, smokers consume significantly lower amounts of dietary fiber than nonsmokers, a total of $11 \%$ or 0.9 grams lower in terms of fiber density under model II. Sixty-three percent, or 0.7 grams, of this lower intake is through direct effect, indicating the substantially different dietary patterns of smokers and nonsmokers with the same level of fiber information. The lower level of smokers' awareness of fiber-health linkages is also quantitatively important, reducing fiber density by two-tenths of a gram. Our result backs up the previous finding by McPhillips, Eaton, and Gans that smokers eat a less-healthful diet, and specifically, consume less dietary fiber than nonsmokers. Such dietary behavior on the part of smokers may be related to the evidence that smokers underestimate health risks relative to nonsmokers (Viscusi).

Although vegetarians constitute only $3 \%$ of the sample, they form the most distinctive population subgroup in the dietary fiber profile. Controlling for other factors, vegetarians, on average, consume about $23 \%$, or 1.7 grams per 1,000 calories, more dietary fiber than nonvegetarians. Not surprisingly, having better awareness and attitude plays a lesser role in this higher intake than the fact that a vegetarian diet in itself is rich in dietary fiber. Thus, even after controlling for awareness and attitude levels, vegetarians have $14 \%$, or 1.1 gram, higher fiber density than nonvegetarians.

The effects of being on a special diet and usage of a fiber supplement provide further evi- 
dence on the importance of isolating the direct and indirect paths to dietary differences. Since both of these variables are diet-related, one may expect direct effects to dominate. However, the results show that the significant positive effects of these variables are almost entirely due to indirect effects. In fact, diet has a marginally significant negative direct effect, implying that, controlling for information levels, those on a special diet tend to have slightly lower fiber intake than those not on a diet. However, those on a diet tend to possess a higher level of disease awareness as well as a better attitude toward consuming fiber-rich food. This higher information level causes those on a diet to have about a $5 \%$, or 0.35 gram, higher fiber density than those not on a diet. The indirect effects of awareness and attitude are even larger for those using fiber supplements, contributing to about half a gram of higher fiber density for this group compared to those not using supplements.

Finally, as expected, the elasticity of dietary fiber consumption with respect to body mass is negative and significant. For a $1 \%$ increase in body mass, the amount of dietary fiber consumed falls by a tenth of a percent. For a $10 \%$ increase in BMI, this translates to a decrease of 0.08 grams of dietary fiber per 1,000 calories.

\section{Conclusion}

Our results affirm the key role of fiber information variables in determining dietary fiber intake. Among the notable results, while the large effect of vegetarianism is expected, the relative strength of college and postgraduate education is surprising. Our results are in agreement with the findings of Kushi et al. on educational attainment and nutrient intake and support their conjecture that the level of nutrition information may mediate the relationship between educational attainment and nutrient intake.

Findings on the differing effects of race, high school education, age, and income on attitude $v i s$-à-vis knowledge/awareness may be useful in designing and targeting information for nutrition education. For example, the high school educated tend to be no more aware of fiberhealth linkages than those with a lesser education, and therefore, the contribution of disease awareness toward intake is insignificant. However, the contribution of awareness rises considerably for the college educated and even more substantially for those with postgraduate education, whereas the contribution of attitude does not differ much from that for the high school educated. This points to the likely high pay-off for a strategy targeting fiber-health awareness campaigns to those with less than a college education.

The strength of the relationships we have identified should, however, be interpreted subject to an important caveat. To the extent that the survey questions underestimate the true awareness, attitude, and knowledge levels, our results will underestimate the effects of these variables on fiber intake. Mismeasurement can result from such factors as the question format and wording. As an example of the impact this may have on the results, consider the attitude questions in table 1. Although the mean fiber density increases from the second to the sixth category for each of the three attitude questions, the first category has a higher mean fiber density than the second, third, and fourth categories for the first two attitude questions. This could be because some respondents are choosing the first category (the option that they consider it not at all important to eat foods with adequate fiber, for example) since they feel they already consume enough dietary fiber. To get an idea of the quantitative effect of this problem, we converted the six-point attitude scale to a two-point scale by combining categories one to four in one category and categories five and six in a second category and reestimated model II. The estimated attitude coefficient increased by $39 \%$ to 0.129 from 0.093 under model II. The attitude variable increased in importance relative to the awareness variable.

A second important caveat relates to the generalizability of our results. First, our sample consists of main meal planners. To generalize the results to a wider population, we need information on the cross effects of meal planners' knowledge and attitude levels on the intakes of other household members. Second, we have focused on a single nutrient-dietary fiber. It would be useful to investigate informational impacts on other key dietary components such as fat and cholesterol.

[Received May 1995;

final revision received June 1996.]

\section{References}

American Cancer Society. Cancer Facts \& Figures1994. Atlanta GA, 1994.

American Heart Association. Heart and Stroke Facts: 1995 Statistical Supplement. Dallas TX, 1994 
Behrman, J.R. and A.B. Deolalikar. "Health and Nutrition." Handbook of Development Economics, vol. 1. H. Chenery and T.N. Srinivasan, eds., pp. 631-771. Amsterdam: North- Holland, 1988.

"Will Developing Country Nutrition Improve with Income? A Case Study for Rural South India." J. Polit. Econ. 95(June 1987):492-507.

Becker, G.S. "A Theory of the Allocation of Time." Econ. J. 75(September 1965):493-517.

Block, G., B. Patterson, and A. Subar. " Fruits, Vegetables, and Cancer Prevention: A Review of the Epidemiological Evidence." Nutrition and Cancer 18(September 1992):1-29.

Bollen, K.A. Structural Equations with Latent Variables. New York: Wiley, 1989.

Brown, D.J., and L.F. Schrader. "Cholesterol Information and Shell Egg Consumption." Amer. J. Agr. Econ. 72(August 1990):548-55.

Capps, O., Jr., and J.D. Schmitz. "A Recognition of Health and Nutrition Factors in Food Demand Analysis." W. J. Agr. Econ. 16(July 1991):21-35.

Chamberlain, G. "Panel Data." Handbook of Econometrics, vol. 2. Z. Griliches and M.D. Intriligator, eds., pp. 1247-1318. Amsterdam: North-Holland, 1984.

Dattilo, A.M. "Dietary Fat and Its Relationship to Body Weight." Nutrition Today 27(January 1992):13-20.

Gould, B.W., and H.C. Lin. "Nutrition Information and Household Dietary Fat Intake." J. Agr. Res. Econ. 19(December 1994):349-65.

Greene, W.H. Econometric Analysis. New York: Macmillan, 1990.

Jensen, H.H., T. Kesavan, and S.R. Johnson. "Measuring the Impact of Health Awareness on Food Demand." Rev. Agr. Econ. 14(July 1992):299312.

Kushi, L.H., A.R. Folsom, D.R. Jacobs, R.V. Luepker, P.J. Elmer, and H. Blackburn. "Educational Attainment and Nutrient Consumption Patterns: The Minnesota Heart Survey." $J$. Amer. Diet. Assoc. 88(October 1988):1230-36.

Lancaster, K. Consumer Demand: A New Approach. New York: Columbia University Press, 1971.

Lee, L.F. "Health and Wage: A Simultaneous Equation Model with Multiple Discrete Indicators." Int. Econ. Rev. 23(February 1982):199-221.
McGinnis, J.M., and W.H. Foege. "Actual Causes of Death in the United States." J. Amer. Med. Assoc. 18(November 1993):2207-12 .

McPhillips, J.B., C.B. Eaton, and K.M. Gans. "Dietary Differences in Smokers and Nonsmokers from Two Southeastern New England Communities." J. Amer. Diet. Assoc. 94(March 1994):287-92.

Muthen, B. "A General Structural Equation Model with Dichotomous, Ordered Categorical, and Continuous Latent Variable Indicators." Psychometrika 49(March 1984):115-32.

"Latent Variable Structural Equation Modeling with Categorical Data." J. Econometrics 22(January 1983):43-65.

Newey, W.K. "Efficient Estimation of Limited Dependent Variable Models with Endogenous Explanatory Variables." J. Econometrics 36(November 1987):231-50.

Pitt, M.M., and M.R. Rosenzweig. "Health and Nutrient Consumption Across and Within Farm Households." Rev. Econ. Statist. 67(May 1985):212-23.

Putler D.S., and E. Frazao. "Consumer Awareness of Diet-Disease Relationships and Dietary Behavior: The Case of Dietary Fat." J. Agr. Econ. Res. 45(January 1994):3-17.

Sobel, M.E., and G. Arminger. "Modeling Household Fertility Decisions: A Nonlinear Simultaneous Probit Model." J. Amer. Statist. Assoc. 87(March 1992):38-47.

Train, K.E., D.L. McFadden, and A.A. Goett. "Consumer Attitudes and Voluntary Rate Schedules for Public Utilities." Rev. Econ. Statist. 69(August 1987):383-91.

U.S. Department of Health and Human Services, Public Health Service. Healthy People 2000. Washington DC, DHHS (PHS) Publication No. 91-50212, 1991.

. The Surgeon General's Report on Nutrition and Health. Washington DC, DHHS (PHS) Publication No. 88-50210, 1988.

Viscusi, K.W. "Do Smokers Underestimate Risks?" J. Polit. Econ. 98(December 1990):1253-69.

Willett, W.C. "Diet and Health: What Should We Eat?" Science 264(April 1994):532-37. 